Portland State University

PDXScholar

\title{
What's Important to You? A Look into the Historical and Social Significance of Buttons
}

Hope JE Ferns

Portland State University

Follow this and additional works at: https://pdxscholar.library.pdx.edu/honorstheses

Part of the Graphic Design Commons, and the Sociology Commons Let us know how access to this document benefits you.

\section{Recommended Citation}

Ferns, Hope JE, "What's Important to You? A Look into the Historical and Social Significance of Buttons" (2021). University Honors Theses. Paper 1034.

https://doi.org/10.15760/honors.1060

This Thesis is brought to you for free and open access. It has been accepted for inclusion in University Honors Theses by an authorized administrator of PDXScholar. Please contact us if we can make this document more accessible: pdxscholar@pdx.edu. 


\title{
WHAT'S IMPORTANT TO YOU? A LOOK INTO THE HISTORIGAL AND SOGIAL SIGNIFICANGE OF BUTTONS
}

\author{
By Hope Ferns
}

An undergraduate honors thesis submitted in partial fulfillment of the requirements for the degree of

Bachelor of Science

in University Honors and Graphic Design

Thesis Advisor

Sean Schumacher
Portland State University

Spring 202I 


\begin{abstract}
This project is an exploration into the social and historical significance of buttons and the culture surrounding buttons. Not only is it looked at from a graphic design context, but it is also looked at from the context of nonverbal communication, social change, and a piece of history that is tangible, accessible, and for all groups of people.
\end{abstract}

\section{$\mathrm{H}$}

umans are passionate beings. We have strong opinions, we share stories, we create art, and sometimes we also create chaos. We want to tell the world how we feel and what we believe in. I became interested in buttons when I was faced with a moral dilemma. My workplace was once a place where I could express myself and wear how I was feeling on my apron, through buttons. "I have high standards" one button read, "Justin's Peanut Butter," another read. They were fun buttons to show off some of my personality without actually being vocal.
The buttons on my apron shifted after the tragic, brutal, and completely avoidable murders of Gorge Floyd and Breonna Taylor at the hands of white police officers. The buttons on all our aprons shifted, our buttons now read "Black Lives Matter" and "racism has no place here"-- because it never has, and we wanted to ensure that it never would. As a team, my coworkers and I collectively gathered to show our support for radical change and did what we could as low-wage workers for a large corporation. We never had an issue with our buttons, until our buttons became about important issues. 
One day, I was called into the office by store leadership. Our dress code had changed.

Without warning, we were told we must take off our pins supporting Black Lives Matter. We were told we could not wear any type of buttons anymore. Buttons were banned from our aprons. Something that brought character and a sense of fun to our workplace had been taken from all of us, because we wanted to care about something bigger than ourselves. When I asked my supervisor the simple question, "why?" His only response to me was "Well, buttons don't really do anything, anyway." In response to my experiences at my workplace, I developed this thesis to look at buttons more closely and provide evidence that buttons do in fact help give momentum to movements.

Buttons have an incredibly rich history that goes back further than imagined. The majority of my research came from the book Button Power by authors Christen Carter and Ted Hake, where button history and culture comes alive. Button Power categorizes buttons based on design, history, and subject matter. Carter and Hake focus on 12 main categories of buttons: advertising, arts \& entertainment, campaigns \& causes, events, icebreakers, nature, organizations, people, places, sports, transportation, war \& anti-war.

By breaking these down categorically, Carter and Hake have made information about buttons widely accessible to more people. Using these categories listed below helps to identify buttons and what they do for people/movements. 


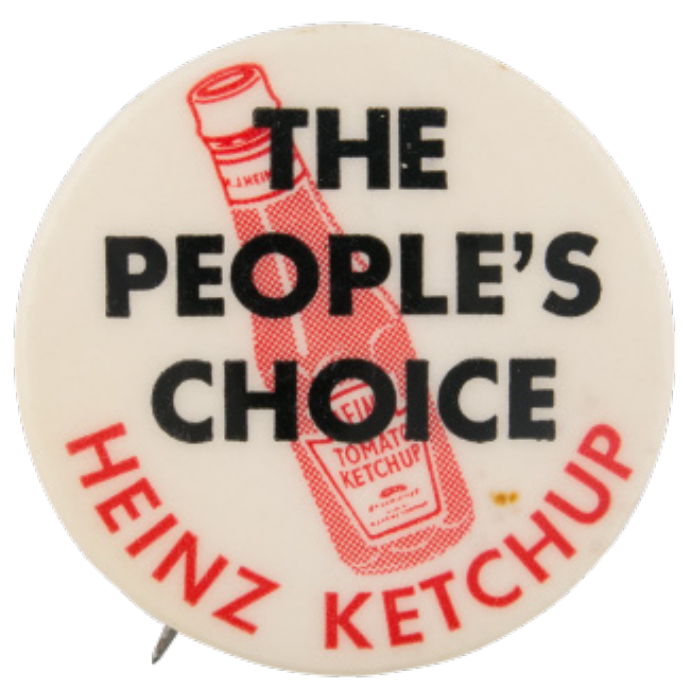

This button for H.J. Heinz Company touts its ketchup as "The People's Choice." Heinz began selling tomato ketchup in 1876, and as of 2012 sold about 650 million bottles worldwide. The company processes 2 million tons of tomatoes each year. Heinz claims its ketchup leaves the bottle at a speed of 0.28 miles per hour. (Busy Bever Button Musem)

(H.J. Heinz Co. (2015). Our company - Trivia)

\section{Advertising}

In I896, owning a visual novelty such as a button was unusual and not nearly prevalent as they are today. With the boom of the Industrial Revolution and new products hitting the market, companies were searching for new and innovative ways to advertise their products. Tiny pieces of art were created to be worn by folks to spread word of mouth about certain products and brands. These buttons became somewhat of a cultural movement, making people feel like they were a part of something bigger or a part of some sort of club for obtaining these buttons.

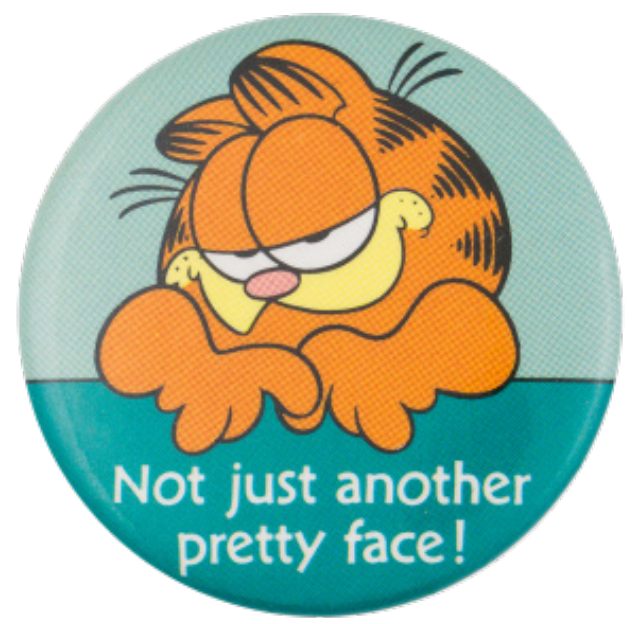

Garfield is a comic strip created by Jim Davis and was first published June 19, 1978. The comic focuses on the adventures of the cat Garfield, Odie the dog and their owner Jon. Garfield the cat is commonly depicted as a lazy, lasagna-loving narcissist who hates Mondays and diets. Since the comic's initial release, Garfield has been adapted into an animated series, television specials, and two movies (Busy Bever Button Musem) C1978 UNITED FEATURE SYNDICATE INC.
The first advertising buttons featured detailed illustrations. They quickly evolved into using photographs and four-color printing processes.

\section{Arts \& Entertainment}

Buttons made their way into the entertainment industry, becoming artifacts that documented over a century of the history of pop culture.

These buttons featured icons from film, television, music, literature, cartoons, and so on. While some buttons were used to solely depict the popular icon(s), some were also used for advertising. This was an early form of celebrity endorsements of products. 


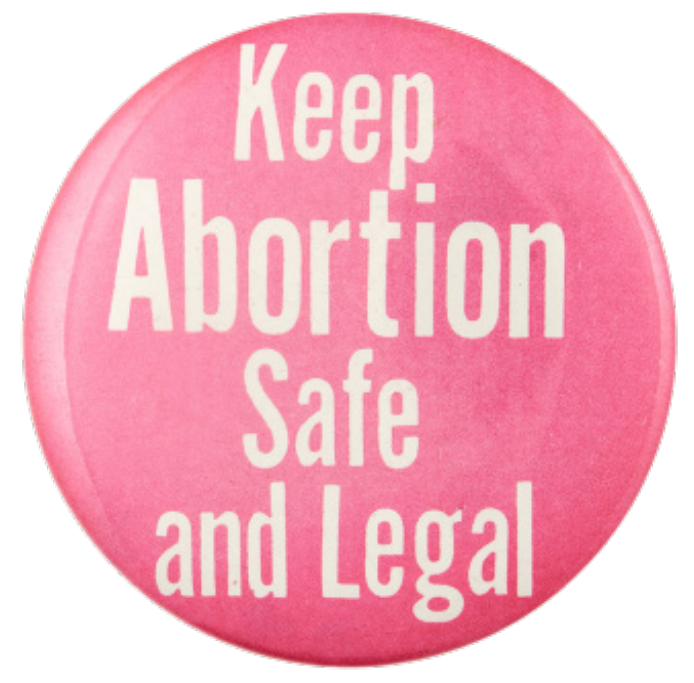

"Keep abortion safe and legal" has long been a slogan of the movement to maintain funding for, and availability of, women's health services. In particular, this phrase speaks to the history of unsafe, undocumented abortion procedures that are undertaken when the medical service is made illegal. The history of abortions in the United States has been a fraught one since it was outlined by Britain in 1803 and started to become coded into law in individual states starting in 1820. Ravitz, J. (2016, June 27). The surprising history of abortion in the U.S. Retrieved from https://www.cnn. com/2016/06/23/health/abortion-history-in-united-states/... (Busy Beaver Button Museum) https://www.buttonmuseum.org/buttons/keep-abortion-safeand-legal-pink

\section{Campaigns and Causes}

Arguably one of the most important categories of buttons, campaigns, and causes buttons to date back to the 1800 sand are a form of showing support for something or someone you believe in. The Emancipation Proclamation in New York, the Franklin D. Roosevelt and James M. Cox campaign, the Civil Rights Movement, and memorializing Stonewall after 50 years are just a few examples of the things the campaign and causes buttons can represent. These buttons really define why people wear what they believe in on their sleeve. With these buttons, it is easy to tell

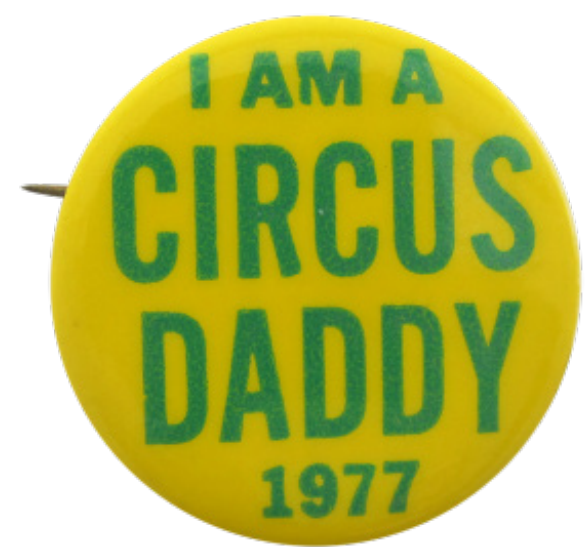

A "Circus Daddy" or "Circus Dad" is somebody who sponsors disadvantaged or handicapped children's fees in order that they could attend a Shriners Circus. Shriner Circuses exist throughout the United States and the proceeds from these events benefit Shriner's Children's Hospitals. (Busy Beaver Button Museum) who someone is voting for, what someone believes in, or what someone supports.

\section{Events}

Event buttons are buttons made specifically for the purpose of advertising special events, memorizing occasions, and to create keepsakes for years to come. Event buttons are a fun way to show other folks what event you have attended/ are going to attend. These little pieces of metal also have a rich background as do most buttons. 


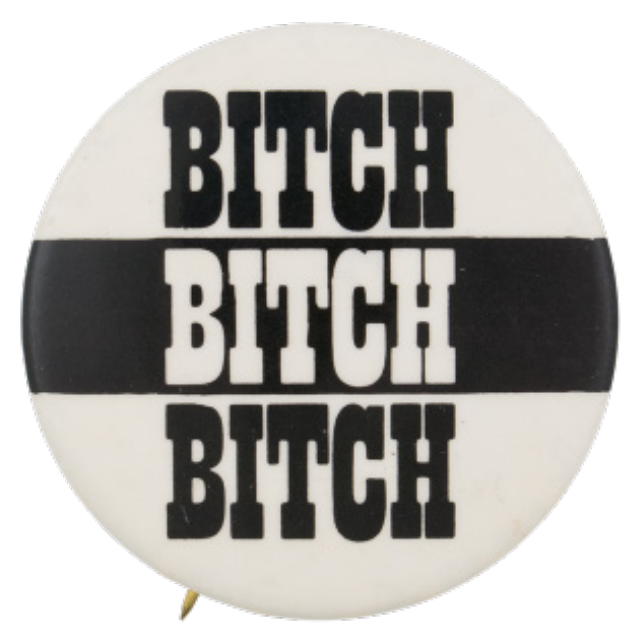

Holoubek Studios Inc. is a Wisconsin based apparel company founded by Verne Holoubek in the 1960s. The company pioneered the heat transfer process that created the iron-on t-shirt popular between 60 s and 80 s. Holoubek Inc. Announces Creation of Holoubek Studios and Heavy Rotation Brand. Prnewswire. Retrieved from http://www.prnewswire.com/news-releases/holoubek-inc-announces-creation-.... (Busy Beaver Button Musem)

\section{Ice breakers}

Buttons are used to open doors and start conversations, the best eampe of this would be ice breaker buttons. Ice breaking buttons are made with the intention of sparking questions and intrigue, possibly confusion. These buttons usually say silly things that might not makes much sense, or say something that you wish to state quite frankly to other humans. Ice breaker buttons are usually humorous in nature and were more widely worn in the I960s-I970s. These buttons sometimes made light of topics that were more taboo to talk about like sex and drugs. Ice breaker buttons are simlar to campign and causes buttons

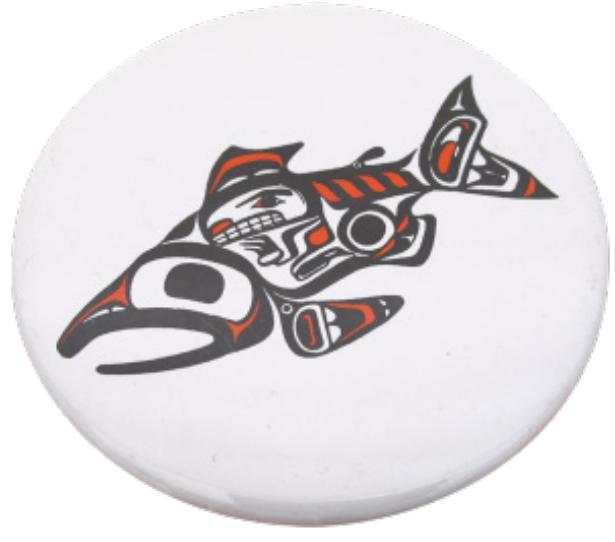

The drawing is named "Skaagi," or more commonly known as "Haida Dog Salmon" by Canadian artist Bill Reid. Reid was born to an European father and a Haida mother. The Haida are indigenous people of the Pacific Northwest, situated in British Columbia, Canada. They are one of the First Nations in Canada. Reid explored his Haida cultural heritage and was deeply inspired by symbols and messages presented in Haida art. Bill Reid Foundation. (2009). The raven's call /L'appel de corbeau. Retrieved August 7, 2014, from http://theravenscall.ca/ (Busy Beaver Button Musuem) https://www. buttonmuseum.org/buttons/northwest-coast-salmon

in that they can show something that the wearer supports, for example the ERA or gay rights.

\section{Nature}

Nature buttons are depictions of places, fruits, flowers, veggies, trees, and anything you can imagine that grows out of the ground. These buttons most commonly used illustrations to show details of the beauty of nature within the small surface of the button. These buttons were intended to show an apostrophe to the state's birds, fruits, trees, etc but evolved into all sorts of natural buttons we see today. 


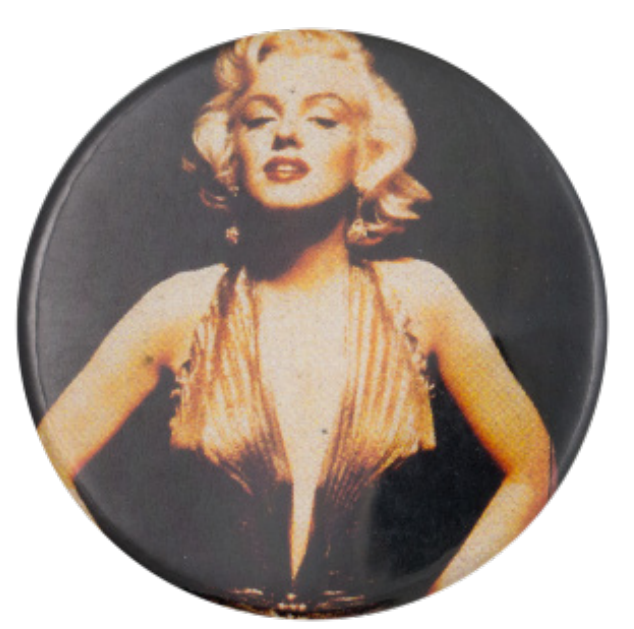

The gold dress shown on this photograph was designed by William Travilla, who was a leading costume designer for 20 th Century Fox in the 1950s. This dress was specifically designed for Marilyn Monroe's role in the movie Gentlemen Prefer Blondes. (Busy Beaver Button Musem, http://www buttonmuseum.org/buttons/marilyn-monroe-color-photograph)

\section{People}

As long as there have been famous folks, we have been putting their faces onto buttons. Some of the more early examples of this, however, were from World War I, when some men would put their wive's photos onto buttons so that they could pin them on themselves when they went to battle. More modern examples however come mostly from celebrities. Just like wearing a cause you support, buttons have made it easy to wear a celebrity you like as well. People buttons can also be clever ways of celebrity endorsement or product placement in button form.

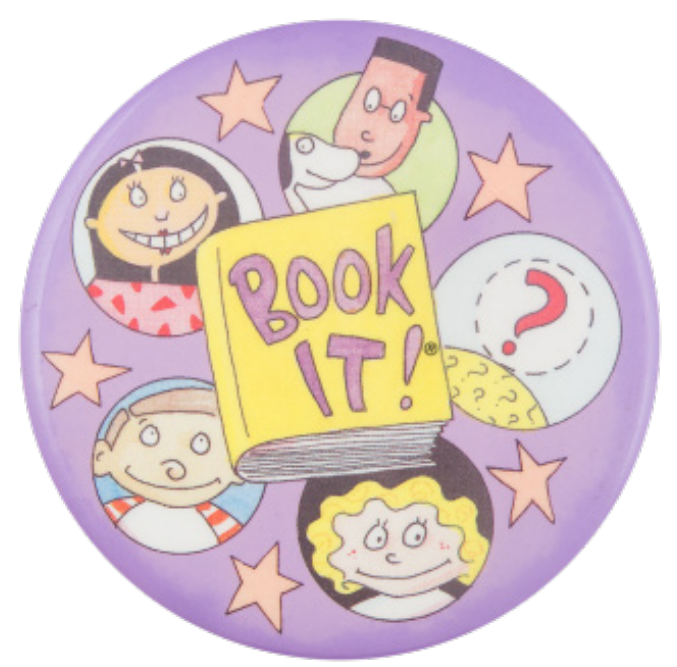

This button comes from the Pizza Hut Book It! Program that was established in 1984 after President Ronald Reagan urged American corporations to get involved in education. The first button for the program debuted in 1985 and the program received a commendation from the White House in 1987. In 1989, Pizza Hut worked with the Library of Congress to help establish National Young Readers Day. Book It! Program. (2013). Retrieved from http://www. bookitprogram.com/About/ ourprogram.asp. (Busy Beaver Button Mueseum) https://www.buttonmuseum. org/buttons/book-it-readers

\section{Oreganizations}

Buttons are a simple and accessible way to tell others how you're feeling, what you do, or what organization you belong to. Buttons became a tool that organizations utilized to gain momentum within communities and also used to spot like minded individuals similarly to the campaign and causes buttons. 


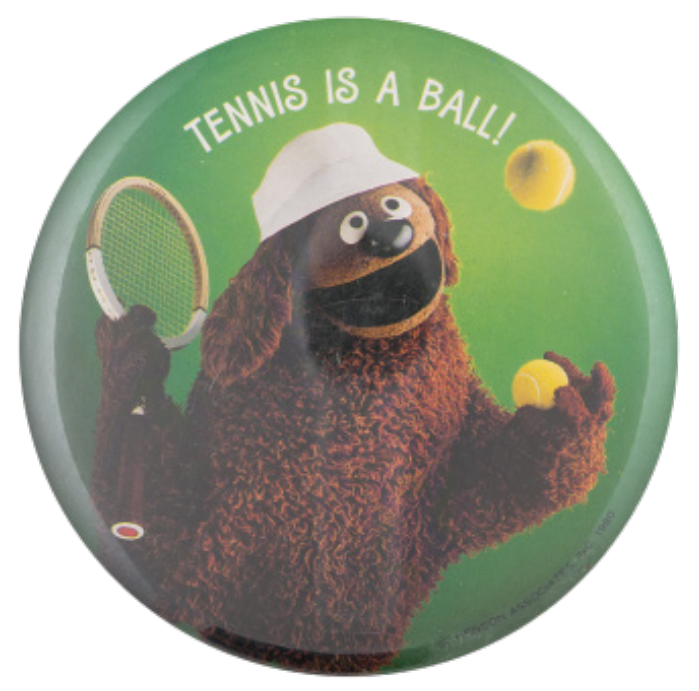

One of Jim Henson's Muppets, Rowlf the Dog, appears on this Hallmark Cards collector pinback button from 1980. The button series featured Kermit the Frog and Miss Piggy as well as other Muppets, and were made with cardboard inserts that could be used as a stand to display the button. (Busy Beaver Button Musuem) https://www.buttonmuseum.org/buttons/tennis-ball

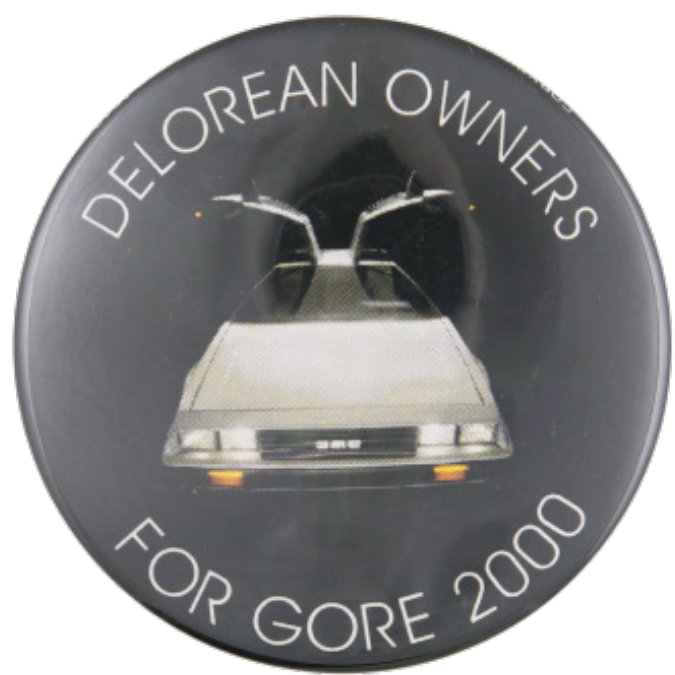

The DeLorean Motor Company was an American vehicle manufacturer from 19751982. They are known for their signature stainless steel sports car DeLorean which featured gull-wing doors. COPYRIGHT 2000 GRAPHIC POLITICS 419-4784513 (Busy Beaver Button Museum) https://www.buttonmuseum.org/buttons/ delorean-owners-gore-2000

\section{Places}

These buttons are fairly self explanatory, they are buttons of specific places. This could be of certain cities, national parks, monuments, or any place in between. Wearing place buttons can signify where a person lives, has visited, or would like to one day travel to.

\section{Sports}

Similar to people buttons, sports are fairly straight forward. Sports buttons were created to show support for teams, or their players

\section{Transportation}

Transportation buttons are buttons that are similar to place buttons, but more focus on the method of transportation.

Transportation buttons can be depictions of cars, planes, trains, boats, ect. Folks that wear these buttons can be travel enthusiasts, work for airlines, or anything really inbetween. 
Author Norda Majekodunmi takes a critical look into overlooked and under-represented groups of people in the paper Talking Pieces: Political Buttons and Narratives of Equal Rights Activism in Canada. Groups including people of color, LGBTQIA+ folks, immigrants, women, ect. Using tools such as political buttons. Majekodunmi states, "behind every political button, there is a potential narrative or story that is not often told." (20I6, 24) Majekodunmi takes a look into under-represented communities and how they use buttons to give themselves visual voices. She examines the Canadian Women's Movement and Black Liberation. Through this article, it is apparent how socially important buttons are. They are an accessible form of design that can liberate and add momentum to movements. Buttons have always been political. Buttons are accessible tools of design used to give a voice to people that may not be able to speak up. Buttons have been some of the most important pieces of design in social and political movements within the last IoO years. It was easy to pin a button on to show up for what you stand for. It was such a simple way to protest, support, poke fun, or shed light on any social issues.

Politics and buttons go hand and hand and we can see that just by looking at the history. Political Buttons and the Material Culture of
American Politics, I828-I976 by Micheal Allen. In this book, Allen gave an in-depth look into the world of political buttons and culture throughout history. Allen describes the strategies around buttons and the distribution of buttons. He talks about how political buttons evolved through time and grew in popularity. You can also see the similarities of the description of how political buttons are accessible forms of design that anyone can wear and use. It is easy to get lost in the extensive world of buttons.

A Very Brief History of Buttons, authored by Busy Button Bever co., is the best way to quickly reference button history, design, and impact. This zine details the overall production of buttons which is helpful for the craft aspect of my project. This zine also breaks down buttons categorically just like Button Power. After spending time and researching the rich history of buttons and button culture, my project began to form. 
With the background and research of buttons in mind, the focus now shifts to my thesis project, which was a project surrounding the idea of finding out what matters to people. What would people put on the bodies to represent themselves? What do they stand up for? What are they not afraid to tell the world? What is important to them?

The project itself consists of 3 parts, buttons submissions, found buttons, and my personal button designs.

Button Submissions: I called for submissions of buttons for about 4 months from my local community. I marketed to designers, non designers, friends and family, and anyone else I could think of. The point of the button submissions was to gather information on what matters to different people. What are some things that folks would wear on a button given the opportunity? I drafted a worksheet and let folks create whatever kind of design they wanted. After gathering around 20 plus submissions, I hand made each one. I set out to create every single button that was submitted.

I wanted to fill a room/wall with these buttons for people to come and view (safely). I ended up filling up a jean jacket with the button submissions+my found button collection+the buttons I designed so that this project could be viewed by many people just from the view of walking around on the street.

The meaning behind this is that was wanted to visually represent the impact of these buttons and all the different issues that buttons can support. Using the buttons as a visual representation of the differences and similarities we share and the things that matter to us. 


\section{What's Important to You?}

For my design thesis class, I am conducting research on the history of social and political buttons. As part of my research, I am reaching out to friends, family, fellow students, and fellow humans to answer one question: What's important to you? Please design within the template provided, anything and everything, that is important to you. That can be social movements, politics, people, places, games, etc. It can be illustrated, typography, symbols, anything you feel that is important to you. Questions? Please feel free to reach out to me via email hferns@pdx.edu

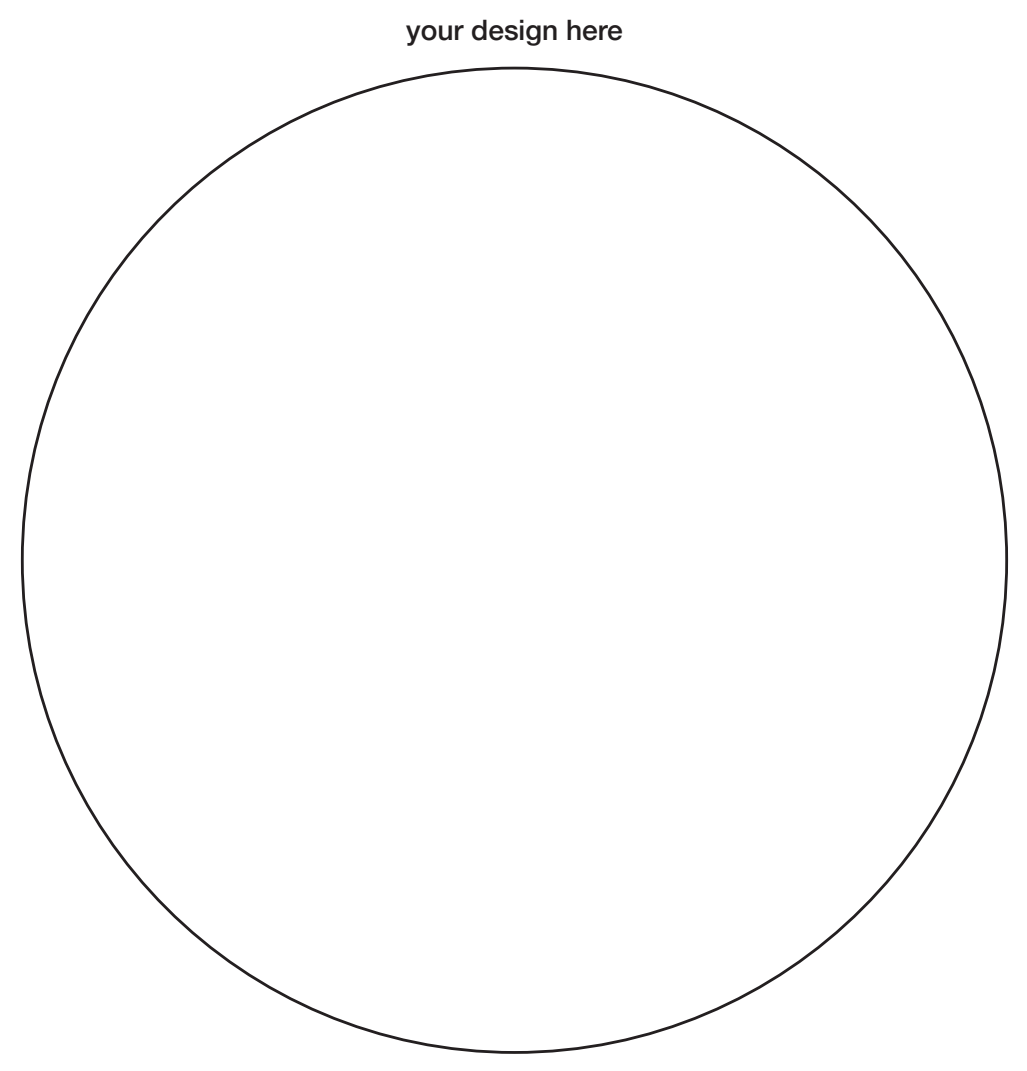

Please email finished designs to hferns@pdx.edu

Button Worksheet that I sent out to folks. I sent it through social media, email lists, and I reached out to folks directly to see about getting submissions 

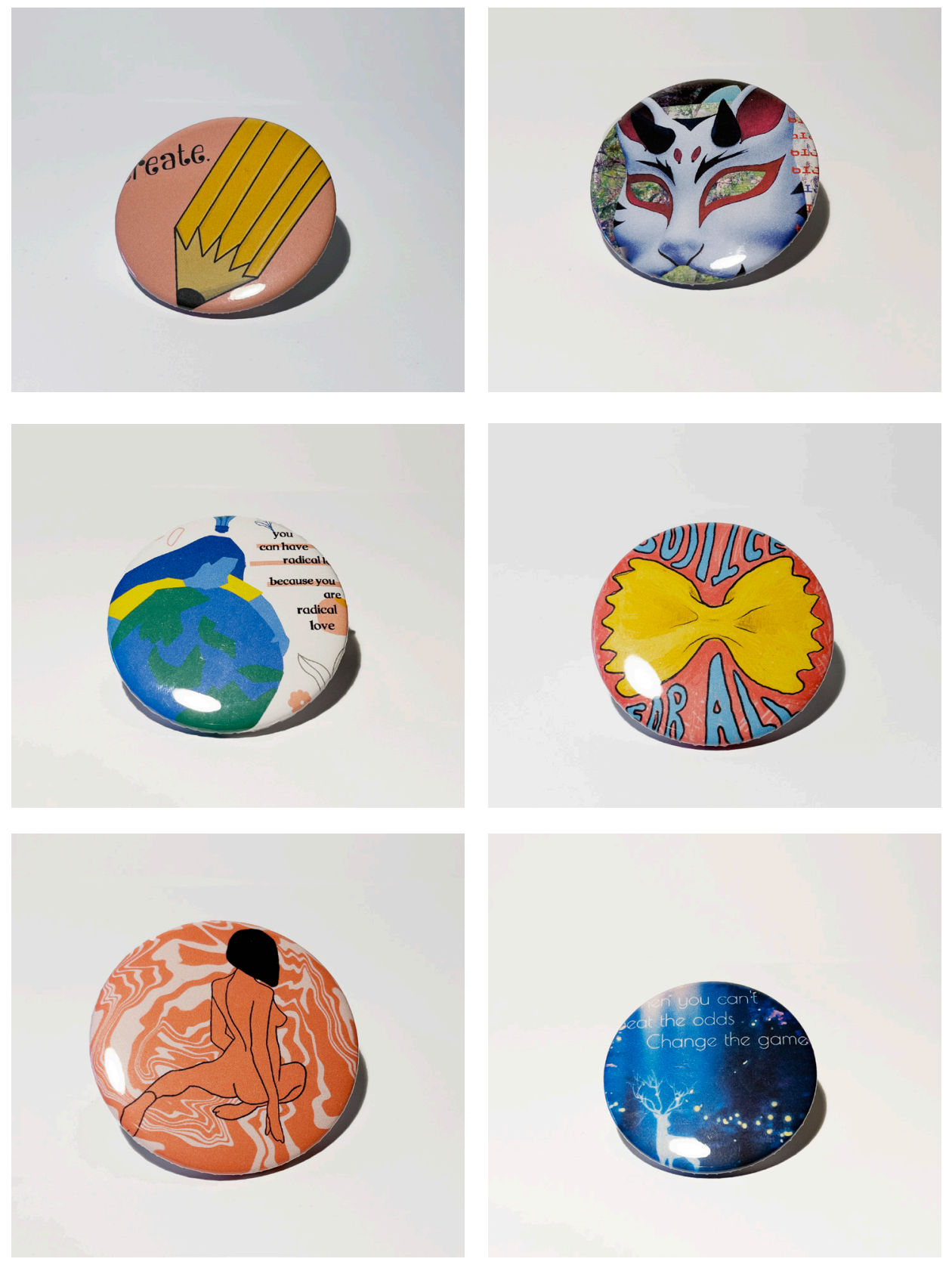

\section{Button Submissions}



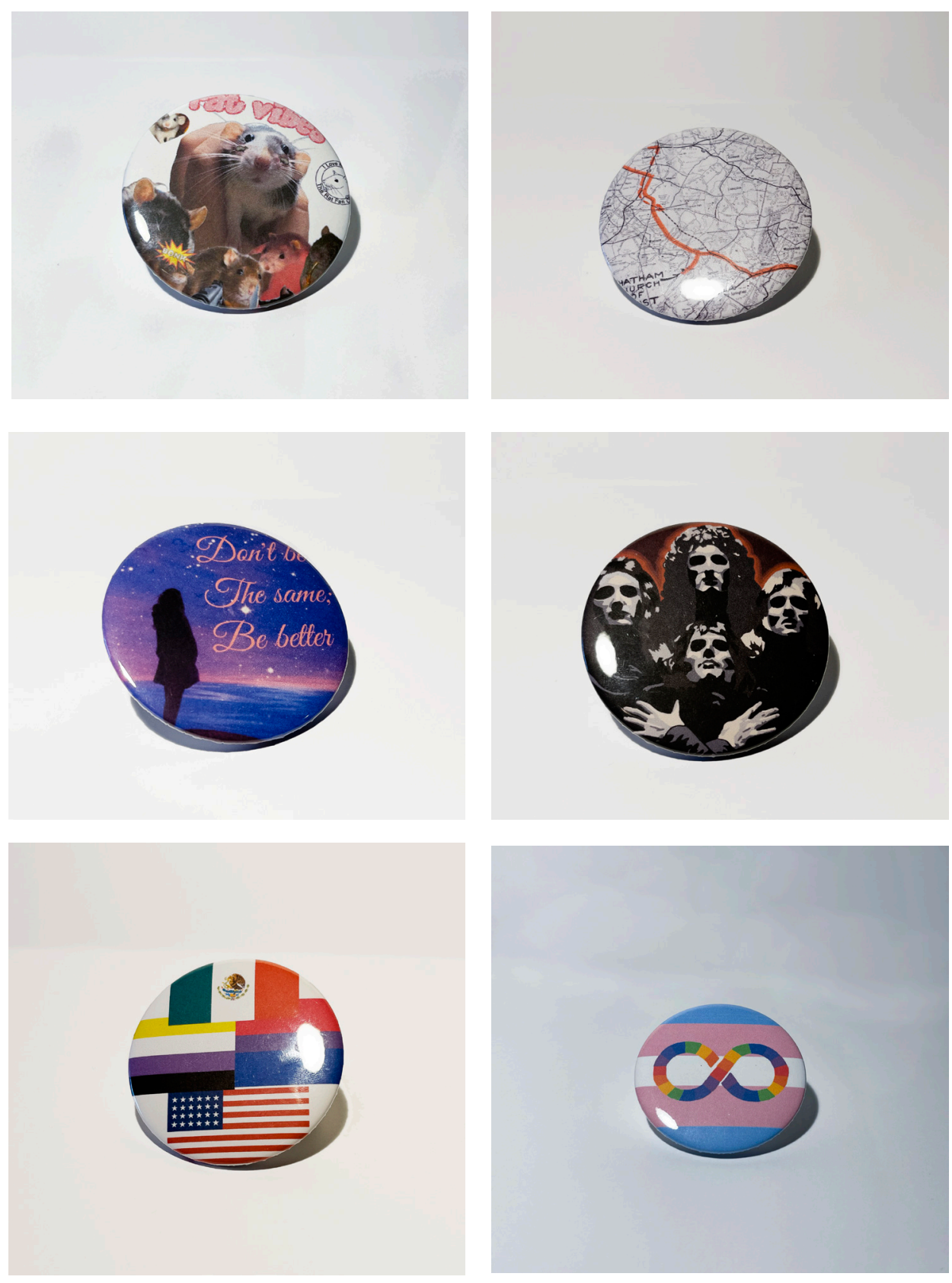

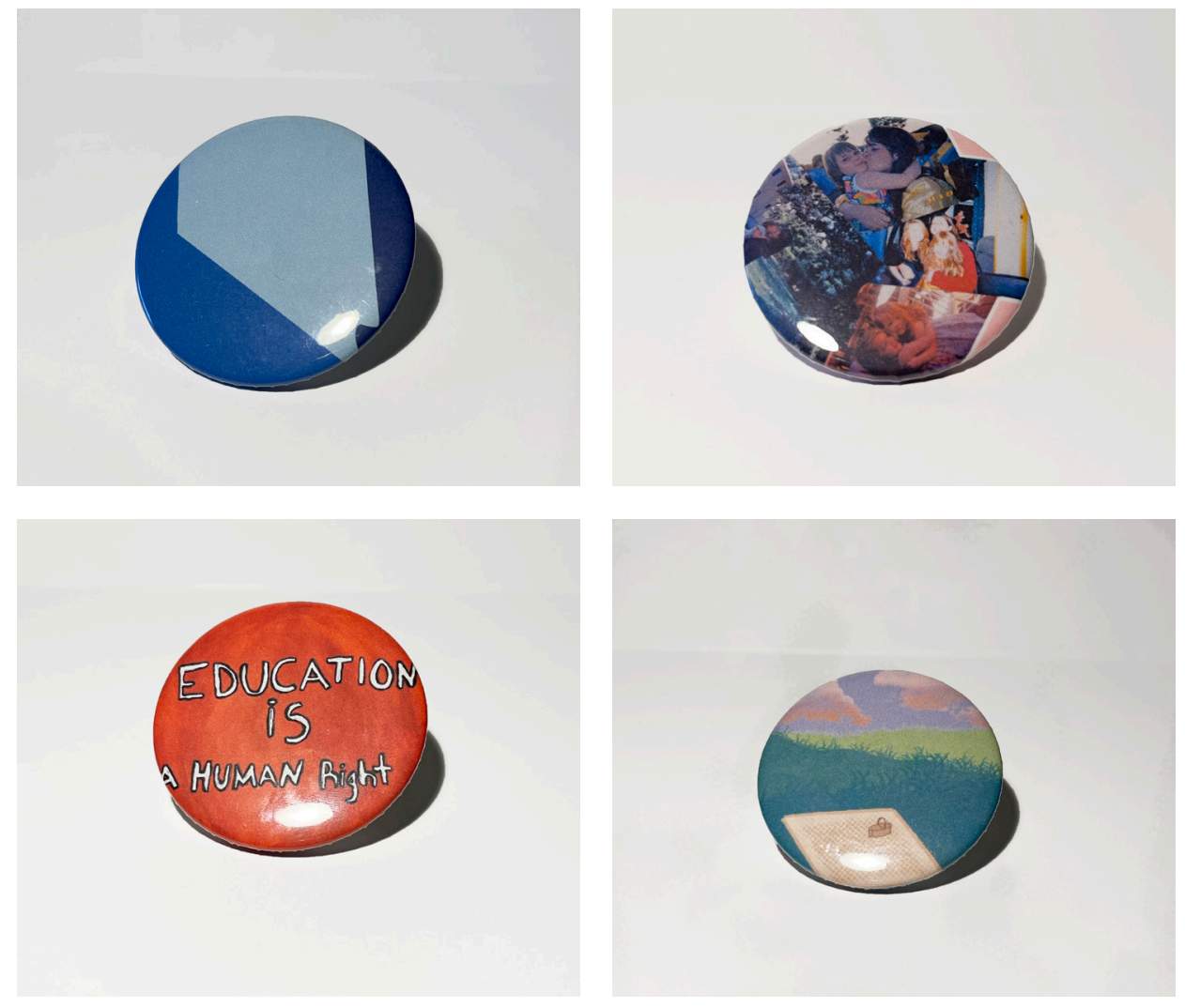

Instagram

a Search

ธ

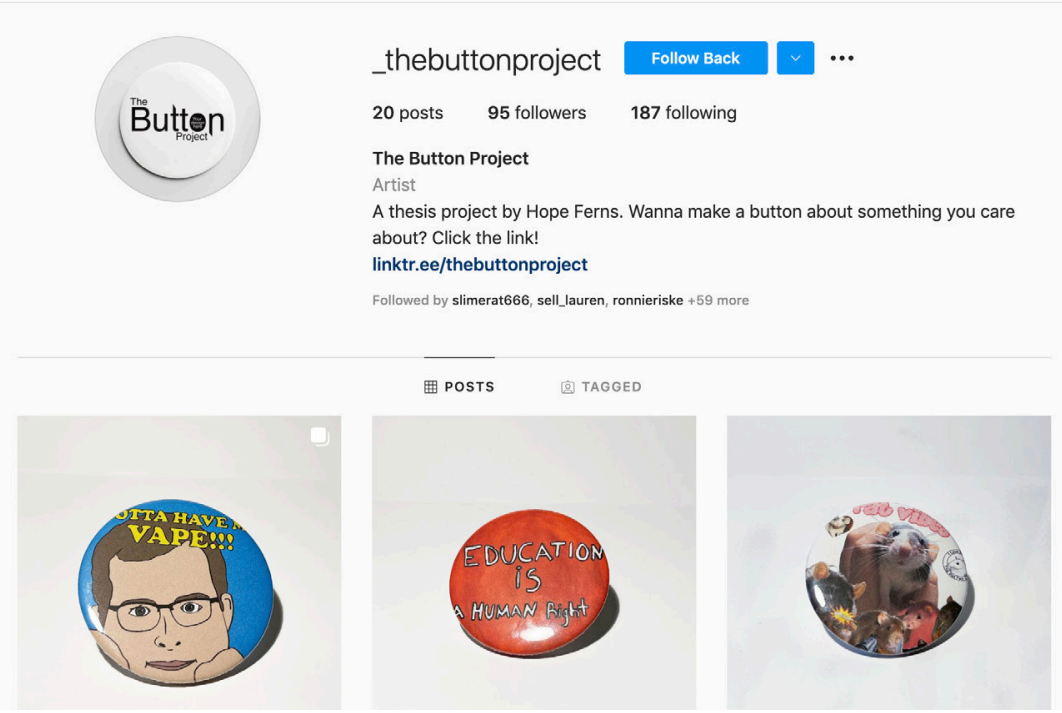

I created an Instagram to archive the buttons and have them live in a digital space. https://www.instagram.com/_thebuttonproject/ 


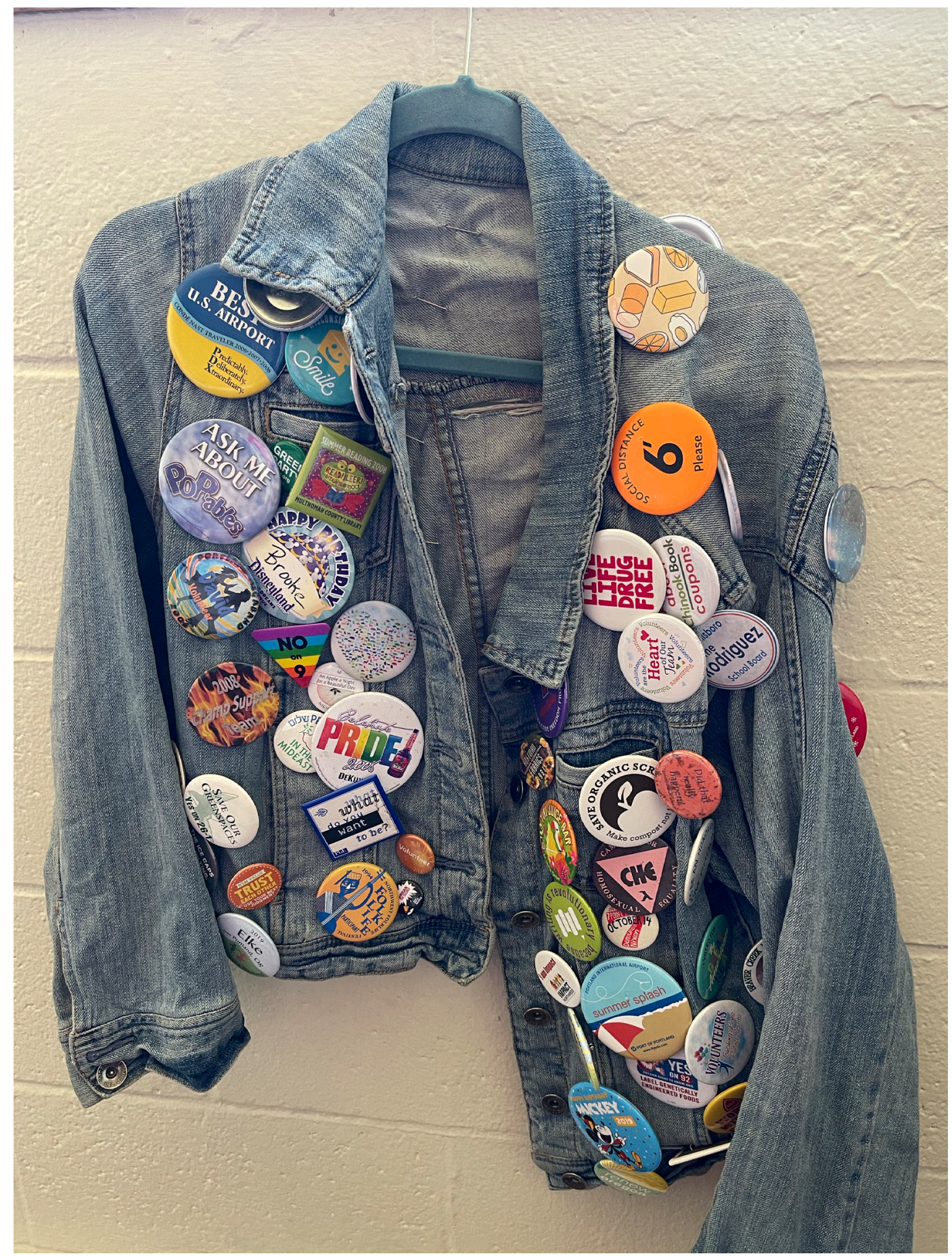

\section{Found Buttons}

Part of this project was going out into the world and finding buttons in the wild. I found around 40 buttons this way that all fell into those different categories described above, by Carter and Hake. By going out into the world and finding these buttons, it enriched the project and provided a real world scope into what I was trying to accomplish. I set out to find buttons in the wild that fit into the categories of this project. I spent a few weeks shopping around and collecting all sorts of fun and interesting buttons. I added them all to the jacket. I hope to find even more and completely cover the jacket in buttons. 


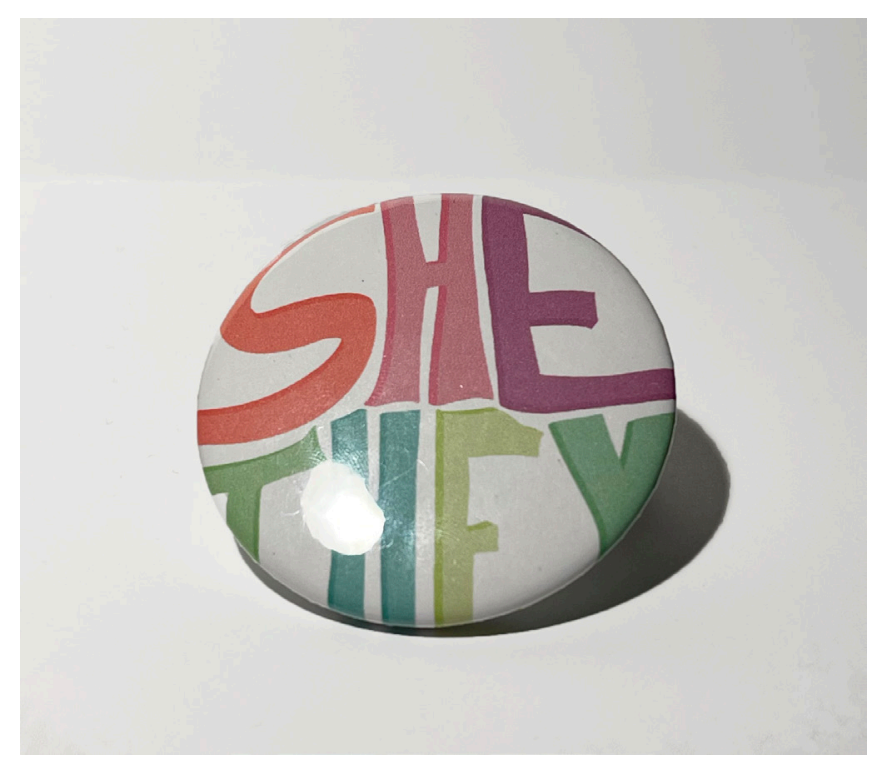

For my ice breaker button, I chose to represent my pronouns. I think pronoun buttons are a great way to break the ice and create a safe and welcoming enviorment for all folks

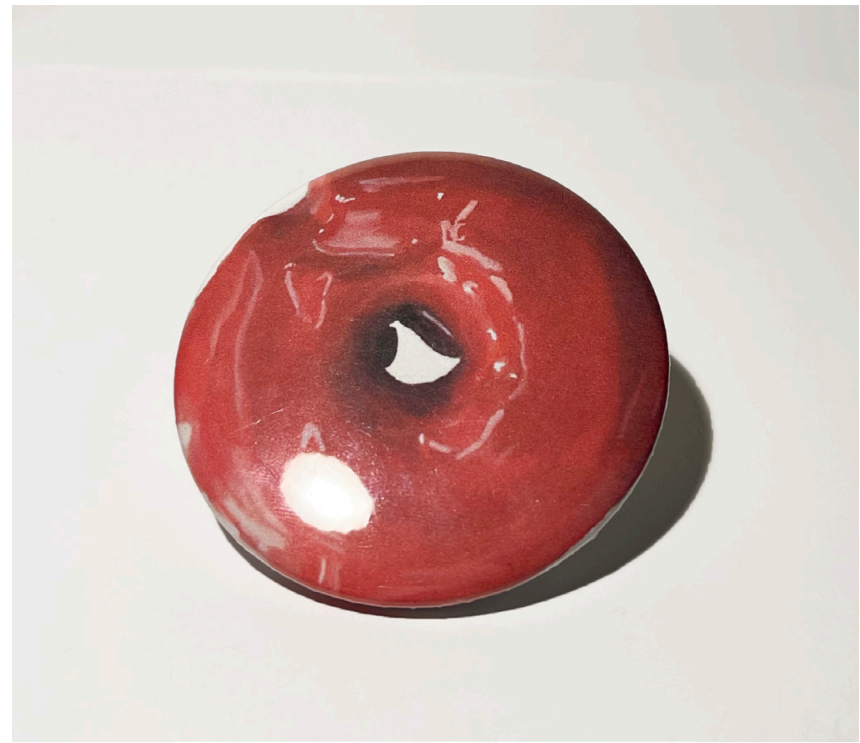

For my places button, I drew a Blue star donut. Blue star was a donut place famous in Portland Oregon. Over the past few years, they have unfortunately been dispersing. This donut pin memorializes blue star.

\section{My own buttons}

Another part of this project was to create my own button collection based off of a few of the categories from Button Power and incorporate things that felt important to me. I wanted to not only reach as many people as possible with this project, but also find connection within myself to things that I would want to wear on my body and showcase to the world using only visual language. 


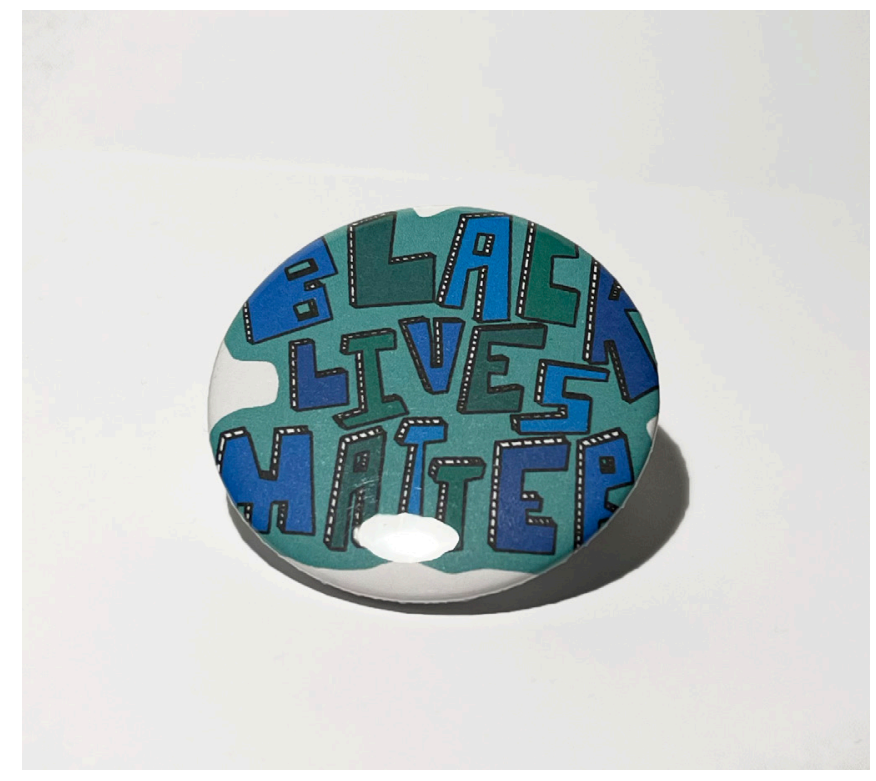

For my causes pin, I went with the message "Black Lives Matter". Black Lives matter is a statement that every person should be saying. Black lives have been underrepresented, black lives have been taken by police, they have been over jailed. It is overdue that black voices are being heard and that folks from all races regconize the systemic racism that is infecting America

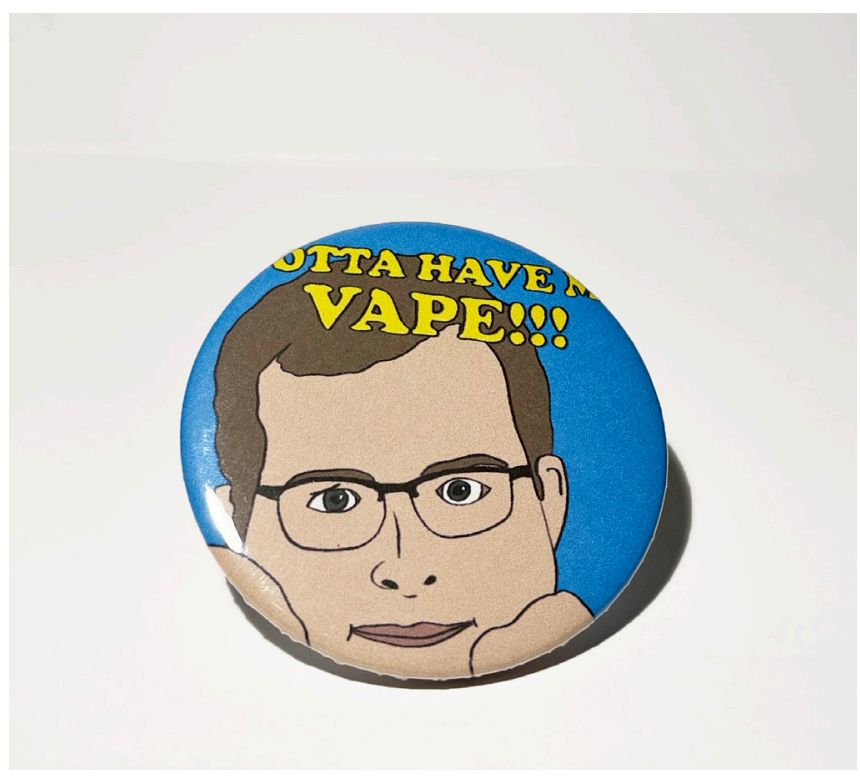

For my arts and entertainment button, I chose to depict my favorite pod cast boy, Griffin McElroy. This could button could also fall under the people category. I chose Griffin because his pod cast with his brothers has really helped me through a lot 


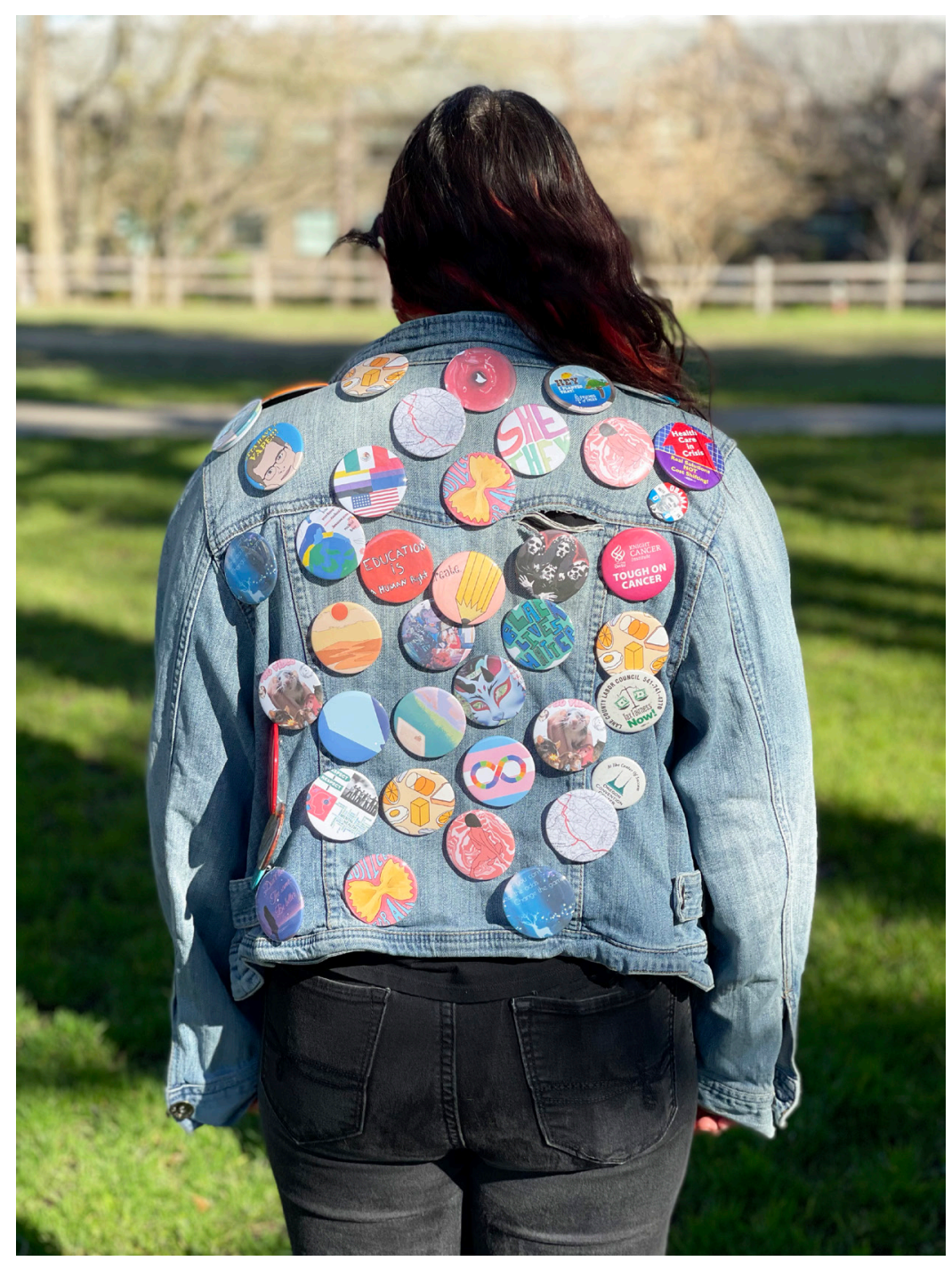

\section{Finals}

The final part of the project was displaying all sets of buttons onto this jean jacket. The found buttons, the submitted buttons, and my own button collection. This jacket is a walking exhibit of buttons history and buttons in motion communicating visual language to the views. My friend Liz was a gracious host of the jean jacket, we talked around the streets of portland showcasing all of the buttons.
In conclusion, I became interested in buttons because I became angry. I became overwhelmed with the sense of being powerless. I became curious about why buttons do matter so much to so many people, movements, events, etc. I wanted to know what is important in this world, and how we can show it. I became excited about buttons when I uncovered the history. I became passionate about buttons when I found out the impact they can have on the world. 


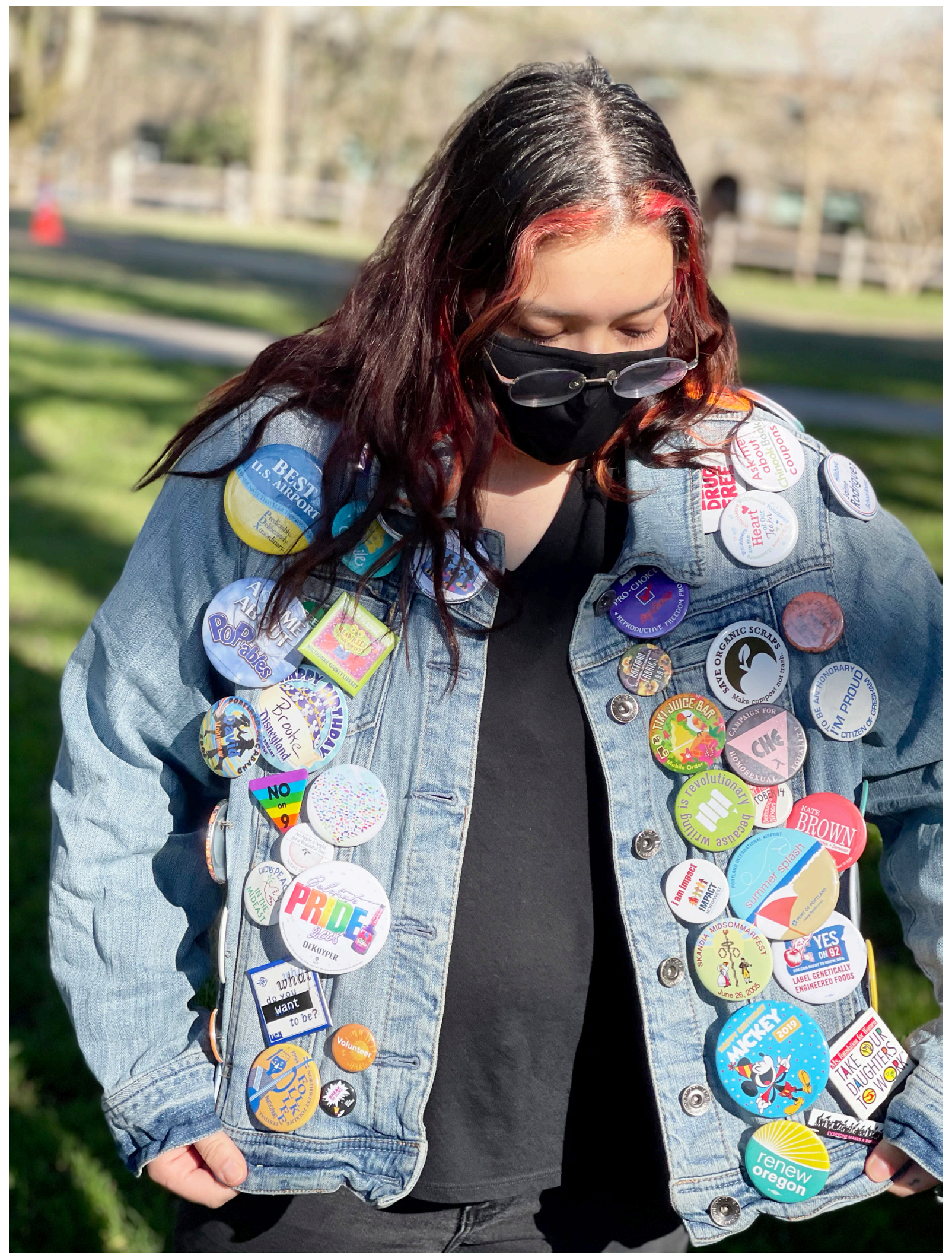




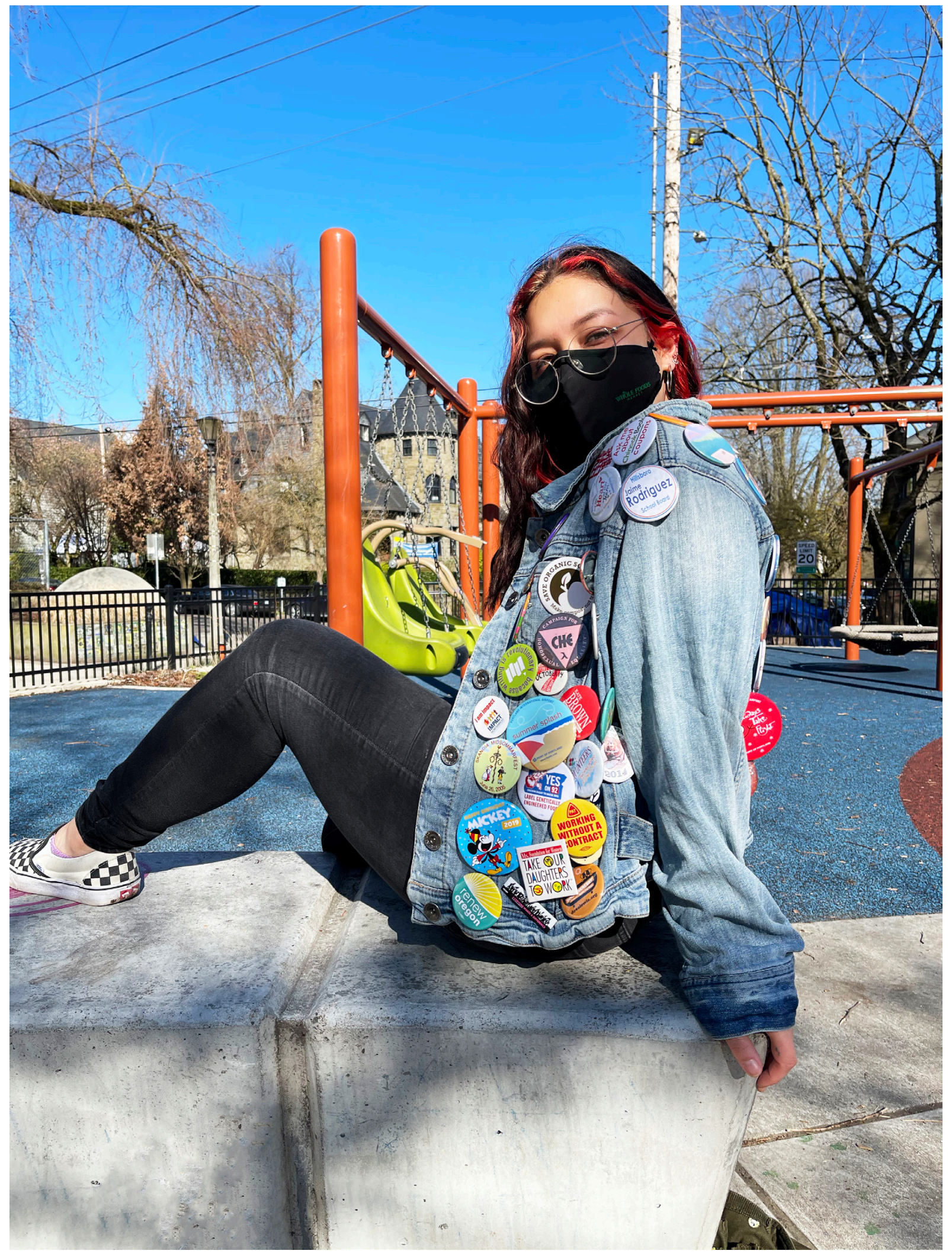




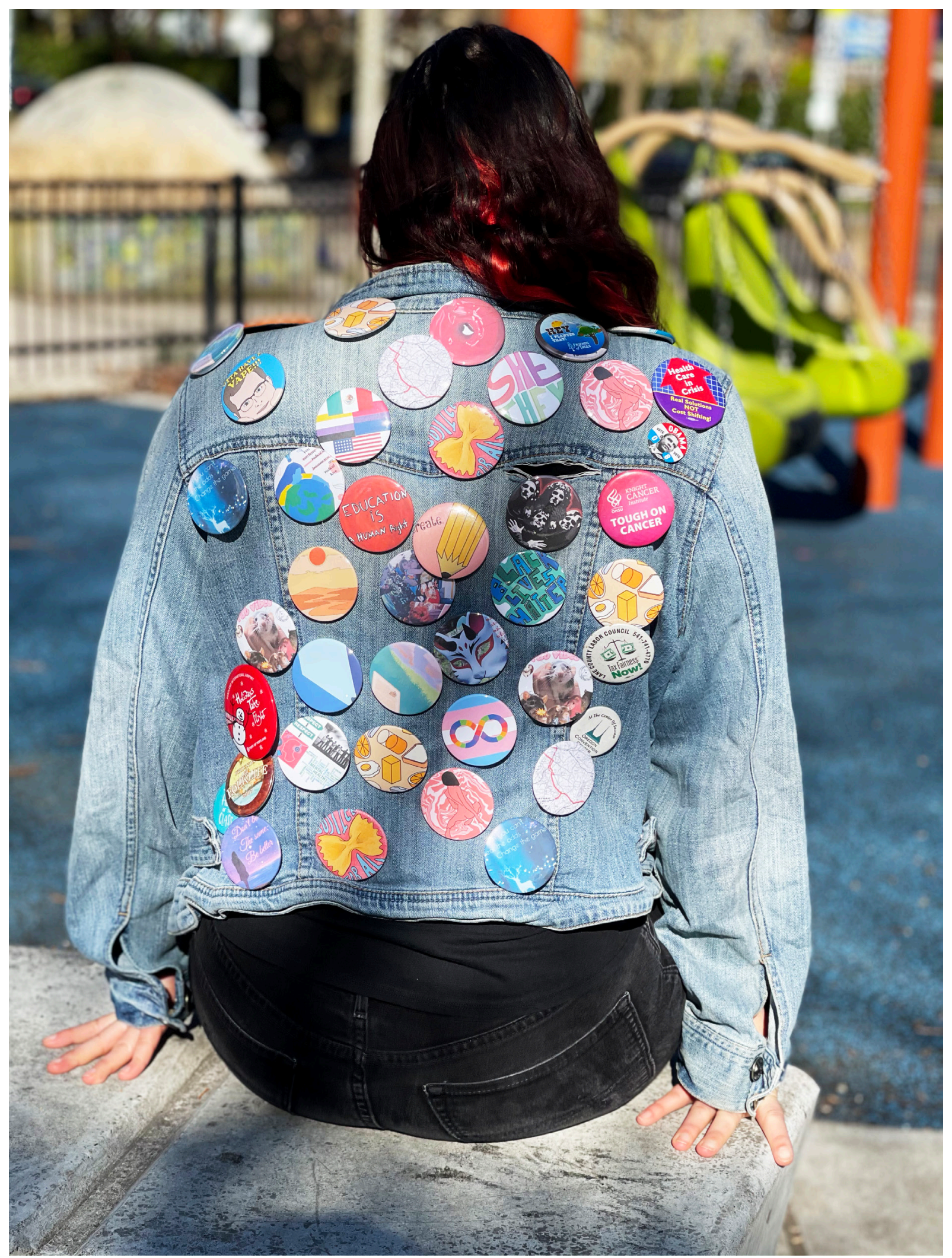




\section{Bibliography}

Carter, C. Hake, T. (2020) "Button power, 125 years of saying it with buttons". Book. Princeton Architectural Press, New york

Majekodunmi, N. (2016). Talking Pieces: Political Buttons and Narratives of Equal Rights Activism in Canada. Journal of Black Studies, 47(7), 753-772. Retrieved May 19, 2021, from http://www.jstor.org/stable/26174184

Allen, M. (2007). Political Buttons and the Material Culture of American Politics, 1828-1976. The Pacific Northwest Quarterly, 99(1), 30-33. Retrieved May 19, 2021, from http://www. jstor.org/stable/40492044

Busy Beaver button co. Hake, T. "A very brief history of buttons" Zine

Busy Beaver Button Museum. (n.d.). https://www.buttonmuseum.org/. 